\section{Objecthood at the End of the World \\ Anime's Acting and its Ecological Stakes in Neon Genesis Evangelion}

Stevie Suan

\section{Performing Selfhood}

Neon Genesis Evangelion (EVA) appears to have an obsession with selfhood. Such a concentrated focus on selfhood is made explicit, for example, in the TV series' enigmatic, but optimistic, final episodes 25 and 26. This emphasis is also evident in how the anime's narrative directly connects the protagonist's examination of his selfhood, something that would initially appear intimate and localized, to the results of global destruction. While the direct linkage between personal introspection and large-scale catastrophe is taken up throughout the TV series, it is perhaps the clearest in the ending of the feature film The End of Evangelion (below, EoE). Much darker in tone, it lacks the positivity of the TV series ending. Despite their overlap with regard to depicting an introspection of selfhood, on closer inspection, these two endings present differing concepts of selfhood and relations to the world.

Often, discussions on EVA's approach to selfhood focus on the human subject. Frequently explored through an explicitly psychoanalytical framework, there is a general tendency to provide readings of the protagonist Shinji's (among other characters') psychological journey. Indeed, EVA features overtly Oedipal themes (Shinji's relationship with his father, and his mother's clone, Rei) and an abundance of visual imagery that reflects 'the act of seeing' (an emphasis on globular and eyeball imagery), which readily lends itself to such

\section{How to cite this book chapter:}

Suan, S. 202I. Objecthood at the End of the World: Anime's Acting and its Ecological Stakes in Neon Genesis Evangelion. In: Santiago Iglesias, J. A. and Soler Baena, A. (Eds.). Anime Studies: Media-Specific Approaches to Neon Genesis Evangelion. Pp. I35-I 80 Stockholm: Stockholm University Press. DOI: https://doi.org/IO.I6993/bbp.f. License: CC-BY 4.0 
interpretations (cf. Endō I997; Kotani I997). To cite one such reading by Tōru Endō, the general thrust of the narrative into the psycheboth into the mysterious architecture of the headquarters of NERV (the organization building the Eva units), and Shinji's mind-readily invites the consideration of larger, philosophical questions that deal with pressing issues of selfhood (I997: 83). This movement inwards becomes central to EVA's association with the hikikomori phenomenon, where people shut themselves off from the world by never leaving their homes. One standard reading is to see the 'pulling into oneself' as indicative of hikikomori and otaku practices, and the EVA endings as directly attacking these by viciously exposing their psychology. ${ }^{1}$ So great is this approach toward psychoanalytically analyzing EVA that Tsunehiro Uno critiques it, regarding the "pulling into oneself/ psychological" (hikikomori/shinrishugi) tendency in readings of EVA as emblematic of a general mode of intellectual thought at the time (Uno 2008: 69-7I).

However, many such readings tend to elide a focus on anime's performance as a media-form. In particular, it is important to consider that in animation there may be different ways of performing selfhood. It is not simply that someone (or something) exists and acts as their selves naturally, but how they act (or not) can be regarded as the attestation of their selfhood (or denial of it), all expressed through their movement. That is to say, the performance of movement in animation constitutes the moving object as an actor. Indeed, this capacity of animation, according to Ursula Heise, enables animation to depict a world where human subjects and non-human objects are all seen as active agents with agency and selfhood, allowing us

I. Takashi Murakami features EVA prominently in his essay in the catalogue for his Little Boy exhibit (2005). It should be noted that hikikomori and otaku may overlap, but they are also distinct from each other. to "inquire into their 'objecthood" (2014: 303). Although Heise notes that anthropocentric views of selfhood can be mapped onto the active object, animation still allows an exploration of alternative modes of existence through the direct visualization of objects moving as actors. 
With this in mind, the performance of movement by objects in animation can be seen as a site for the analysis of the selfhood enacted by the actor (the active object), whether human or non-human. This can be conceptualized through notions of performance from the theater, where certain types of acting presuppose certain types of performance of the self: for someone to act as someone or something else, we have to presume there is a type of self that the actor can act as, and consider the means by which to present that type of self. As such, there are various modes of existence which are brought into being through certain modes of performance, ultimately enacting a type of selfhood in the process. Similarly, in animation, there are different ways of performing movement and, consequently, the actors become constituted in a manner afforded by the tendencies of the mode of performance utilized. In other words, how an object (human or non-human) performs constitutes the acting object as a specific type of actor based on the movement they enact, and thus realizes a tendency toward a certain type of selfhood-the types of which under consideration here are labeled 'individualism' and 'objecthood' (see Suan 2017).

Taking this as a point of departure, a very prominent mode of performance that deserves consideration is what Donald Crafton calls embodied acting (2013). Built from classically modern notions of human stage acting, embodied performance enacts characters not just through the sequence of actions that they perform, but through the subtle gestures and looks they make, movements which seem to originate from inside them, defining them as a person. Dramatic criticism traditionally involves this type of performance, judging characters on their being 'round' and having an interior that holds their depth of personality. On stage and in film, actors are usually expected to play a very different character than themselves, to present a new self through acting whose interiority is indicated through subtle motions of the eyes, minor gestures and bodily gesticulations, as if that character were really performing those actions (and not an actor 
playing another self). The process gives rise to highly individualized movements that differentiate one character from another, locking it to that body to enforce its uniqueness, and presenting a discrete inside/ outside boundary for that self.

However, such embodied acting tends to build an anthropocentric view of selfhood through those actors' performances. This is what happens in films like Beauty and the Beast, where not all the objects in the film are active, but only a select few, such as the candlestick Lumière and the clock Cogsworth. Each object has their own peculiar types of movements that are specific to their character and body shape; each is individualized in the process. But, in terms of the narrative, these objects are actually humans that were turned into those objects and later return to being human, providing a succinct example of how the above noted type of embodied acting actually enacts human-like sensibilities in something that is non-human, through the mode of performance in/of animation. Put bluntly, embodied acting as commonly performed in animation tends to hone in on the specific type of selfhood that is human individualism, even if performed through non-human characters, for better or for worse.

There is another important type of performance of/in animation which Crafton labels figurative acting. In this mode of performance, codes and patterns are utilized to produce a self; conventionalized gestures that pre-exist and are external to each specific character are employed. In anime, these codes include facial expressions like arched eyes for happiness or glimmering eyes for overflowing emotions, all cited from prior instantiations of those codes by other characters. Consequently, performances of selfhood via figurative acting do not evince the same inside/outside boundaries for expression as individualism. Such dynamics are supported by anime's own media-form: figurative acting is sustained by anime's conventionality itself, extending beyond EVA to a variety of different anime productions from which these very same codes are cited. It is these operations of figurative 
acting that are called into focus in the TV series ending, as if examining the very idea of performing selfhood through figurative acting in anime's media-form. This effectively visualizes anime's tendency to embrace a type of selfhood that might be called 'objecthood,' a tentative term for a mode of existence that builds on Heise's view of active objects and Timothy Morton's conception of 'objects.'2 Objecthood can be considered as a type of selfhood (or rather, a mode of existence enacted as a type of selfhood) that is non-human (but does not exclude humans), whereby one is constituted as an object made up of other objects and in relation to other objects-in this case, a character constituted by figurative acting codes from other characters.

It should be noted that there may be other ways of performing selfhood than figurative and embodied acting, but both are prominently featured in EVA. Moreover, though these modes of performing selfhood are usually enacted in their extremes; they are not found in complete isolation, but rather in a tense relationship with each other-one always implicated in the other, even if just barely: embodied performance usually employs movements that are individualized, but must retain something recognizable (and thus repeated/repeatable) for the gesture to be legible (e.g., a smile, tears); otherwise it is so 'individual' it is overly abstract, isolated and unintelligible. Not all figurative codes are performed exactly the same, making them specific to their instance of enactment. This mutual implication is evident in EVA, where we do not find a strict division of types of selfhood, but a general retention of their mutual implication, keeping taut the tensions of these modes of performance in/of animation for humans and non-humans.

Throughout the EVA series, modernity's assumptions are turned on their head, as objects of human creation, the Eva units, boldly display their agency: they exhibit performances of embodied acting, appearing with the same autonomy as human individuals. At the same time, humans are broken into fragments, their psyche examined in parts as
2. This also includes reference to the ideas of Bruno Latour. 
they delve into their interiors to find only more parts of other characters, interrogating the constitutive codes of figurative acting. These two modes of acting are mutually implicated throughout the EVA series, favoring one extreme or the other in different sequences as the anime probes their respective tendencies toward each type of selfhood (individualism and objecthood), even though one tendency is never completely subsumed by the other.

As if a culmination of exploring the extreme ends of these tendencies in the performance of selfhood, the TV series and film endings can be read as inverse images of each other. The former lands on the examination and embrace of objecthood via the operations of figurative acting, whereas the latter depicts the dynamics of the extreme tendency of embodied acting, focusing on human individualism, and directly tying such a selfhood to the ecological catastrophe of the end of the world. Leaning heavily toward the tendencies of the extreme of figurative acting, the TV series ending presents a sense of selfhood that resembles the operations of a more ecological mode of existence close to Morton's conception of objects. For Morton, this is needed to counteract the modern, human-focused autonomous individualism which carries with it disastrous ecological consequences: maintaining a strict sense of inside 'human me' and outside 'environment' (composed of non-human objects), the human individual subject is seen as in control of non-active objects; consequently, pollution or global warming do not actually affect humans, as they are simply external objects that cannot act.

Instead, Morton sees humans and non-humans both as active objects, each consisting of "a potentially infinite regress of other entities" (2017: I05). Here, inside and outside are thoroughly blurred, because 'I' am both inside the 'environment' and the 'environment' is inside 'me.' This means that the pollution is not 'out there,' it is in the air I breathe in my lungs; it is me, in some sense, just as the biosphere is what I depend on to exist. In such a configuration, 
global warming can now be seen as acting upon me as it too is an active object, deeply affecting myself and my life. As the final episode presents a sense of selfhood that distinctly leans toward the operations of figurative acting, where the self is made up of various different codes (something like an active object made of other objects, where the classically conceived borders of inside/outside of individualism do not operate quite the same way), it appears more in line with Morton's ecological mode of existence, one which the optimistic tone of the finale seems to endorse: the final image of the series depicting Shinji performing a figurative acting code for smiling.

While ecological readings of EVA may initially seem out of step for the anime, it is important to consider that EVA is clearly set during the Anthropocene (the geological era where humans are the greatest influencer of climate and environmental change), constantly addressing the issue of humanity's devastating impact on the world: the Second Impact, the cause of the disaster that reshaped the world of the series, was in fact induced by humans. Furthermore, the collapse of the environment is consistently mentioned throughout the series, as by the elderly school teacher droning on in front of the class, or the mention of the strange seasons here and there, the reason why there are the iconic cicadas, a sign of summer, constantly ringing all-year-round. It is also a part of the surrounding media discourses and events around the time of production and release, in particular the Kyoto Protocol in 1997, which extends the I992 UN Framework from the Convention on Climate Change. Ecological concerns are even overtly shown in the megahit anime Princess Mononoke, which was also released in 1997.

Released the same year, the film EoE reveals a startlingly different view of the ecological stakes of performing selfhood compared to the TV series ending, with depictions of environmental disaster that are more overt and bleak. Indeed, EoE features scenes of lush forests (filled with a concealed military) early on in the film, and ends with 
scenes of a dead landscape made desolate by humans. Since the entire film's conclusion turns on the destruction or salvation of the world as decided by one individual (Shinji), EoE can be read as exploring how selfhood and global devastation are linked. While the optimistic TV ending leans toward the tendencies of figurative acting and its operations of interrelated objecthood, in contrast, the filmic ending is far more pessimistic, moving toward the dynamics of individualism in the extreme of embodied performance, displaying the ecological destruction of this type of selfhood. The filmic ending takes the ideals of modern individual agency and its discrete inside/outside divide to its logical conclusions, but simultaneously undercuts it, as the individual decisions of Shinji inside of himself lead to the external destruction of Earth (for which he is not the catalyst), even as he reaffirms the barriers between people to uphold individualism, evincing an ambivalence of individual agency. The resulting destruction of the world is subsequently presented as linked to the operations and agential assumptions of the performance of anthropocentric individualism, exposing the impasses of its ability to attend to ecological catastrophe.

\section{Embodied Acting and Human Control of Objects}

While examples of embodied performance are scattered throughout the series, episode I9 contains one of the most memorable sequences in the TV anime: when Eva-or goes 'berserk' beyond Shinji's control, viciously destroying the Angel, miraculously operating without a power source (Fig. 5.I: 20:20-2 I:25). Performed by key animator Mitsuo Iso, in place of the movements commonly seen in fight sequences of robots piloted by humans (often mimicking human combat, with sword slashes and gun blasts), Eva-or executes a wild and brutal beating on its Angel opponent. Once thought to be a giant robot piloted by a human, Eva-or shatters this concept by scuttling on all-fours and devouring an 

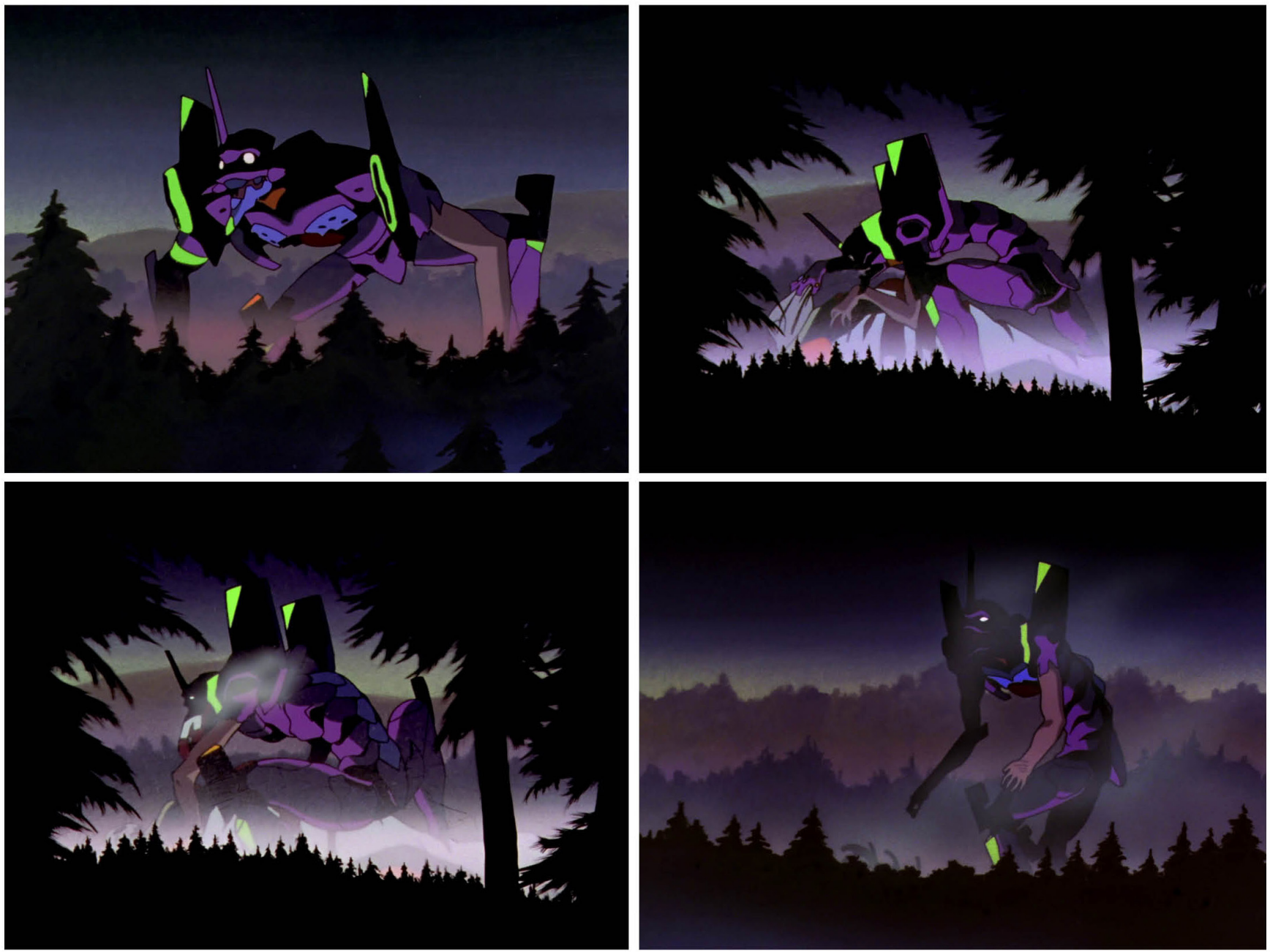

Angel like a carnivorous mammal in a humanoid figure. Much of the savagery of the Eva unit is articulated through the bestial movements performed, making it a prime example of embodied acting.

In this mode of performance in/of animation, "animators perform Figure 5.1. Eva-or going berserk in episode 19 , presenting a savage autonomy through embodied acting. () khara, inc.

movement to perform emotion," effectively giving the impression that the animated bodies are expressing themselves through their speci- 
fic gestures and actions (Crafton 2013: 44). Embodied acting is thus 'introverted,' and tends toward the constitution of modern individuals that appear to provide a sense of depth in their enactment of emotional movement (2013:36). Such a performance is partly afforded by full animation, which, according to Thomas Lamarre, employs "closed compositing," hiding the gap between the layers of the celluloid images, a tendency toward the movement-into-depth of cinematism and, in character animation, a heightened sense of sentiment in character acting (2009: 200). Historically, it is through Disney's innovations in the I930s that embodied acting is developed, whereby the 'fullness' of the animated movement is used to give the impression that it is an individualized actor whose inner emotions and drives command the movement that is expressed externally.

This is heavily indebted to Konstantin Stanislavski's acting method, where an actor internalizes a character and expresses their personality not just in words, but in the manner in which they execute actions and gestures. Disney in fact had his animators take acting lessons and observe human actors trained in this mode of acting (Crafton 20I3: 37-4I). What occurs in embodied performance is a manner of controlling the body to operate through the insertion of individualism by creating interiority. The emphasis on control is similar for both human and animated actors. Embodied performance gives the impression of naturalness, a sense of internal motivation that appears to organically originate from inside the character expressed in its movement, and consequently hides how trained and constructed the production of that movement is (by actor or animator). This applies even if that character is controlled by someone else, even if the movement will emphasize that their 'original self' is somehow under another's control due to the discrepancy between the 'original' and 'controlled' movements of the character.

All in all, the effect of embodied acting is one of a character with a sense of emotional depth, that is, emoting from the interior, but expressed externally in the movement. The point to stress is that 
embodied performance tends to be associated with depth, and in the case of its execution in animation, a spatial dynamic whereby there is a discrete inside and outside to the character, isolating it from the external world as it operates with full autonomy. This emphasis on autonomy links to a modern idea of 'realism' in this type of acting. As Crafton notes, a sense of scientific realism underpins the development of embodied acting developed by Disney in the I930s (2013: $4^{\mathrm{I}-42}$ ). Depth is once more foregrounded here: Disney seeks to produce interiority as expressed through the individualized movement of the characters-their exterior movements providing a way for viewers to grasp the depth of the character's uniquely emotive personality to make them seem 'realistic.' Although this deviates from Crafton's conceptualization, it is important to stress the connection of this type of realism to anthropocentric individualism. Indeed, it often appears as if embodied performance in animation imitates the emotive movements of people in the real world, even if the animated objects are non-humans. Simply put, embodied acting produces humanistic individualism, with all its depth and personality, in the performing objects.

But this might be a double-edged sword. On the one hand, it does allow the easy acceptance of a world of moving non-humans, providing a simple means to display how, through the animation and its subtle movements, it is not just humans that have complex depth and agency, as Heise contends (20I4: 309-3 IO). On the other hand, it is a thoroughly anthropocentric selfhood performed by the non-humans. EVA seems to bring this tension into focus, succinctly encapsulated in the bodily movements of the Eva units, supposedly non-human objects that turn out to be close to humans, which display a depth that (from a modern perspective) should not be there.

Indeed, although one of the central themes of the EVA TV series is the mastery of the world through human scientific control, the series displays not just the immense prowess of the modern scientific human, but their fragility, their gaps in understanding and 
3. Much of the conception of the modern divide between human subject controlling non-human object is drawn from Bruno Latour (I993).

4. See Ida Kirkegaard's Chapter 2 on 'bank cuts.' their lack of control of the non-human, even those of their own creation: the Eva units. There are multiple instances referencing the hubris of humanity, obliquely asserting the role of anthropocentricism, of the human at the top, distant and distinctive from all other life. In some sense, the dream of modernity, of the human subject controlling the object, is encapsulated in NERV and SEELE (the enigmatic parent organization of NERV) which create the Eva units, objects which are supposed to be simple tools to defeat the Angels. NERV (and SEELE) tend to follow a modern approach to science, of subjects who calculate to control and manipulate nonhuman objects. ${ }^{3}$

However, while the Eva units initially evince the human prowess for control of the object, right from the beginning the Eva units themselves defy this simplistic view: episode 2 shows Eva-or going berserk, beyond Shinji's control as it defeats the Angel, and later episodes show the cracks in understanding of their operations for the lead scientist Ritsuko Akagi. Eventually, the attacking Angels and the Eva units themselves are revealed to be somehow close to human. But this is not just in the dialogue. The Eva units are portrayed as having their own agency through their animation via embodied acting. It is important to repeat that in EVA embodied acting tends to be seen not in the human characters, but in the actions of the Eva unit's themselves, carefully animated in a manner not employed by the human characters. In fact, most of the Eva unit battle animations are not reused bank footage (which are frequently utilized for human characters), ${ }^{4}$ further attesting to how much emphasis went into producing unique, individualized movements for each combat sequence.

With that in mind, returning to Eva-or's bestial actions in episode I9, this embodied performance provides a vivid display of agency (in this case, to literally be active and enact effects on its own, even without a source of power), a sense of a primal, savage character. 
Importantly, this sequence reveals both the isolation and agential capacity of individualism, so distinct it is difficult to relate to, so autonomous it cannot be controlled. Because it is an Eva unit, such a performance reveals the actual agency of the non-human, dispelling the divisions between humans and non-humans, reversing modern conceptions of inanimate object (one that humans can control) and active (human) subject. Yet, as if insisting on resistance to any strict divisions, in the narrative, Eva-OI is an object of human construction operating on its own; at the same time, Eva-o I maintains at least a tinge of humanity as it is, in fact, the remnants of the soul of Shinji's mother (Yui Ikari), which are somewhere inside it.

\section{Objecthood and Figurative Acting}

It is not just objects that blur the divisions between human and non-human through their performance in/of animation in EVA. Contrary to the Eva units, the humans stay within anime's recognizable brand of figurative acting, which is in part supported by the prevalence of limited animation in anime. Although the figurative codes used in anime are not usually critiqued, limited animation's prevalent display of jerkier movements is often scorned. The long-standing valorization of the movement of full animation as the standard for animation (even in Japan) might also be connected to the valorization of embodied performance as the measure of quality character acting in/ of animation.

However, limited animation has its own dynamics of movement. At times, holding still images for nearly a minute, as Lamarre notes, EVA optimizes limited animation's techniques of working with layers and using stills to produce, what he calls, "hyperlimited animation," highlighting the flatness of the image, presenting its own manner of compositing, editing and producing motion in animation (2009: 202). Investigating the type of limited-animation compositing employed by 
EVA's central production studio, GAINAX, Lamarre theorizes the "exploded view," a quasi-orthogonal perspective, where the parts (or layers) are separate, but also assembled, a tension of unity and multiplicity in this alternative structure of depth. This is not the movement-into-depth of cinematism, but the impression of depth spread across the surface in a sequence of images. We can see this in the commonly used trope of a character or vehicle avoiding a barrage of missiles, as demonstrated by Asuka in her Eva-o2 in the EoE film (25:04-25:07). Such sequences tend to "flatten the hierarchical ordering of the image. It is impossible to say whether any one element in the perceptual field is intrinsically more important" (Lamarre 2009: 136). For Lamarre, "instead of one-point structuration to produce depth with distinct positioning, the structure of exploded projection generates fields of potential depth traversed by lines of sight ... the result is very close to a logistics of information retrieval," whereby viewers are "asked to skim and scan fields, and to discern degrees of separation or connection in the manner of a network" (2009: I36).

Such limited animation dynamics, where potential depth rises to the surface providing a different mode of perception, can be seen as overlapping with figurative acting. Operating differently than embodied acting, figurative performance utilizes a combination of familiar expressions. In its extreme, it is only predicated on the repetition of codes, in the process producing a sense of surface as the codes sometimes appear at the same time, or in varying frequencies in the same scene-that is, on the characters, not necessarily in them. This emphasis on surface even appears in character designs. In fact, EVA's characters are seen by Lamarre as emblematic of what he describes as "soulful bodies," where personalities (as potential depth) are inscribed on their surfaces (2009: 20I). Yet it is not just their physical designs that display their character, but also the types of movements these soulful bodies perform. In anime, the prevalence of limited animation affords the regular switching between these 
codified gestures and expressions, often facilitating sudden shifts between emotional registers (e.g., characters going from sad to happy to angry very quickly). Indeed, the 'jerkiness' of limited animation's dynamics allows for the rapid deployment of different types of expressions, often with very little physical movement of the character's body until the next expression is employed in the following frame.

Figurative acting is in this sense closer to contemporary, digitally informed perception: reading, scanning, connecting, jumping between parts and whole. This does not mean that figurative acting is somehow simpler or lacking in skill. It is quite the opposite, as performing figurative acting is incredibly difficult to achieve. Here, the sense of control is measured by the capacity to adhere to the set of codes, which if performed within the appropriate range can be quickly identified and read. Proficiency with these codes, as well as their enactment in combination in a manner that makes the character appear cohesive and not just a dull, incongruous collection of traits is a very particular way of building characters. That one may confuse the collection to be the character is evidence of the prowess in subtlety of figurative acting. In the process, agency and autonomy in the modern sense are muddled: does a human perform the codes, or do they force the human to act a certain way as the codes exist outside the human who must enact them within a specific register to be recognizable; are characters producing the codes or are the codes producing the characters?

All in all, because figurative acting relies on its relation to prior codes, its operations resemble Hiroki Azuma's notion of the database of character parts (what he calls moe-elements, Azuma 2009), where otaku consume (and create) characters by dividing them up into their various (conventional) parts. However, here the elements are the figurative codified expressions; and they do not operate by precise replication, but rather by the act of citation, that is, repeated in different contexts (also implying a sense of change and variation rather than exact duplication). Moreover, each character is enacted 
through the accumulative combination of cited codes, making the frequency and grouping of those codes produce that particular character, which serves to differentiate actors from one another in a manner that is distinct from their visual design.

This process also genders characters, and although the operations of gender via figurative acting in anime are outside of the aims of this chapter, it is worth touching on the topic as an illustration of how figurative codes work in general. To give one example of how gendered codes operate, in episode I2, each character is piloting their respective Eva units, but each Eva unit runs differently (I 8:28-19:00), with Rei's Eva-oo running in a manner that is codified as feminine in anime. Such a gendering is most apparent in the position of Rei's arms and hands (arms spread out to the side), with a slight bounce in her gait, rather than the closed fists of Shinji's Eva-or in his forward-leaning sprint. This is not to say that all codes are gendered, nor that these hand gestures and ways of running fully determine gender. Rather, these codified gestures are often performed by female characters and, following Judith Butler's conception of gender performativity, become associated with femininity, giving them the impression of naturalness when performed by female characters due to a sedimentary effect (I988; I993; I997). Further drawing on Butler, these codes operate as cited instances where each iteration itself becomes a site for further citation, thus sustaining the illusion of 'naturalized gender.' Such an illusion is both sustained by and its operations exposed in the performance of these gendered codes by the Eva units: these movements differentiate each pilot's operations from one another, the femalepiloted robots running with the feminine code; but it also displays how gendering can operate as the performance of codes, as the bodies of the Eva units are not overtly gendered male or female revealing their performativity and the external source of such gendered codes as they express the pilot's mannerisms in the way they are made to run. 
This is also where a little of the embodied acting tendency shines through, as it differentiates each character from one another in an almost individualizing way, especially with regard to Asuka and Rei, who are both running differently, with Rei's movements employing more overtly 'femininely' coded running gestures than Asuka's. It should also be noted that such gendered codes are used in anime to facilitate the common trope of cross-gendering through body swapping (e.g., a female character inhabiting a male body, but performing feminine codes in the male body-utilized in the film Your Name), which is similar to this dynamic of piloting a robot, revealing how important citation is to gender performativity.

In any case, the operations of citation, whereby each instantiation is both a re-enactment of prior instances and a 'source' for further iterations, is fundamental to the performative constitution of the selfhood of characters via figurative acting. Furthermore, as noted above, the frequency of codes performed by actors is important for differentiating characters. There will be characters that smile less frequently or those that are cheerful all the time, which is displayed through the frequency of sterner or more bubbly expressions. This does not mean, however, that characters will not change over time. In fact, an actor's character is produced through a cumulative compounding of the various codes they perform over time. Accordingly, different expressions are added onto that actor's grouping of codified expressions, for instance, when a usually serious character may execute the occasional smile, the rarity of the expression making it all the more meaningful (and thus implying character growth). Furthermore, sudden bursts of expression (such as anger or fear) are not uncommon, making their enactment often comedic or endearing, adding another codified expression onto the compound that is that actor's character.

The result is a character who enacts codes that are specific to that instantiation, but also extending outside of the current citation to the earlier performances of that code. As such, figurative performance operates by linking different iterations of those codes despite their 
distance spatially (they are separate characters) and temporally (enacted at different times). Instead of the anthropocentric individuality of embodied acting, figurative performance enacts 'particularity,' whereby a character is specific, but only as it is made up of iterations in a certain series of codes. Furthermore, when constituting characters through that precise collection of codes, they extend beyond that character outwards to other codes. Indeed, the very capacity to produce a character via figurative acting is premised on prior iterations of those codes in other places and other times on other characters.

With this in mind, it is worthwhile considering what type of selfhood is afforded by figurative acting. Although Crafton does not go so far as to consider this, figurative acting in the performance in/of anime's animation could be seen as constituting 'objecthood' (for lack of a better term): a self that is operating as an object, which is made of, interacting with and dependent on other objects. Here, Timothy Morton's conception of 'objects' and how to think them is instructive, as it greatly differs from the modern view. Instead of autonomous human subjects that act on the passive non-human objects, for Morton, humans and non-humans both exist as objects, here seen as entities that contain "a potentially infinite regress of other entities" (2017: I05). In other words, each object, under closer inspection, might be seen as having other parts, which could also be seen as objects; these object-parts themselves are made up of parts, and so the process continues. Morton sees this as a way to include even humans as "a partial object in a set of partial objects, such that it comprises an implosive whole that is less than the sum of its parts"- that is, if each object has many object-parts, then to consider the object is to also consider the object-parts, which outnumber the singular object itself (2017: 104).

This produces what Morton describes as "a whole that subscends into its parts," various parts that are both somehow external and internal (from the modern perspective) to the object, each always haunted 
by other objects. At the same time, one object is specific, while still retaining the necessity of all the other objects that constitute it. In Morton's model, even if a person were to dig down deep, they might find something that is not themselves, not theirs, and even non-human, because they are entirely comprised of objects, all the way up and down-a self that is constituted of object-parts, making them quite distinct from the sharp inside/outside boundaries of the anthropocentric individual. Figurative acting executes this in a somewhat literal way: the external object-parts of the figurative codes (or in Azuma's terminology, moe-elements) are on the characters; they are 'shared' by many characters, making each character somehow part of the others, but also distinct. For instance, each character has a particular 'personality' because of their codified gestures and expressions, which are cited from other characters who enacted them in prior instances.

An example of objecthood can be found in the human-looking character of Rei Ayanami, often treated in the narrative as an object in the modern sense: without agency and to be acted upon—scientifically produced by humans, even replaceable, as she is one of a series of clones of Shinji's mother. ${ }^{5}$ In this sense, she is an emblem of objecthood and figurative acting: a copy, somehow not human, and built through the repetition of codes to constitute a reserved personality. In terms of selfhood, she would then have the most overtly complex problem: how does she differentiate herself from the other clones of her? Rei even addresses this issue in a monologue on her existence in episode I 4 (I 2:OI-I 4:O7), where she first mentions multiple random objects (mountains, skies, flowers, people, Eva units, blood, etc.), then questions what humanity is, and eventually states that she is an object ("kono buttai wa jibun"- "this object is me") ${ }^{6}$ (Fig. 5.2).

Toward the end of this sequence, when Rei is supposedly delving into herself, she says that she feels someone else is there, and then names a number of the other characters accompanied by their images. This can be read as a very literal examination of how figurative
5. For the most extensive feminist reading of EVA, see Kotani (I997).

6. All translations from the ADV release of the EVA DVDs. 

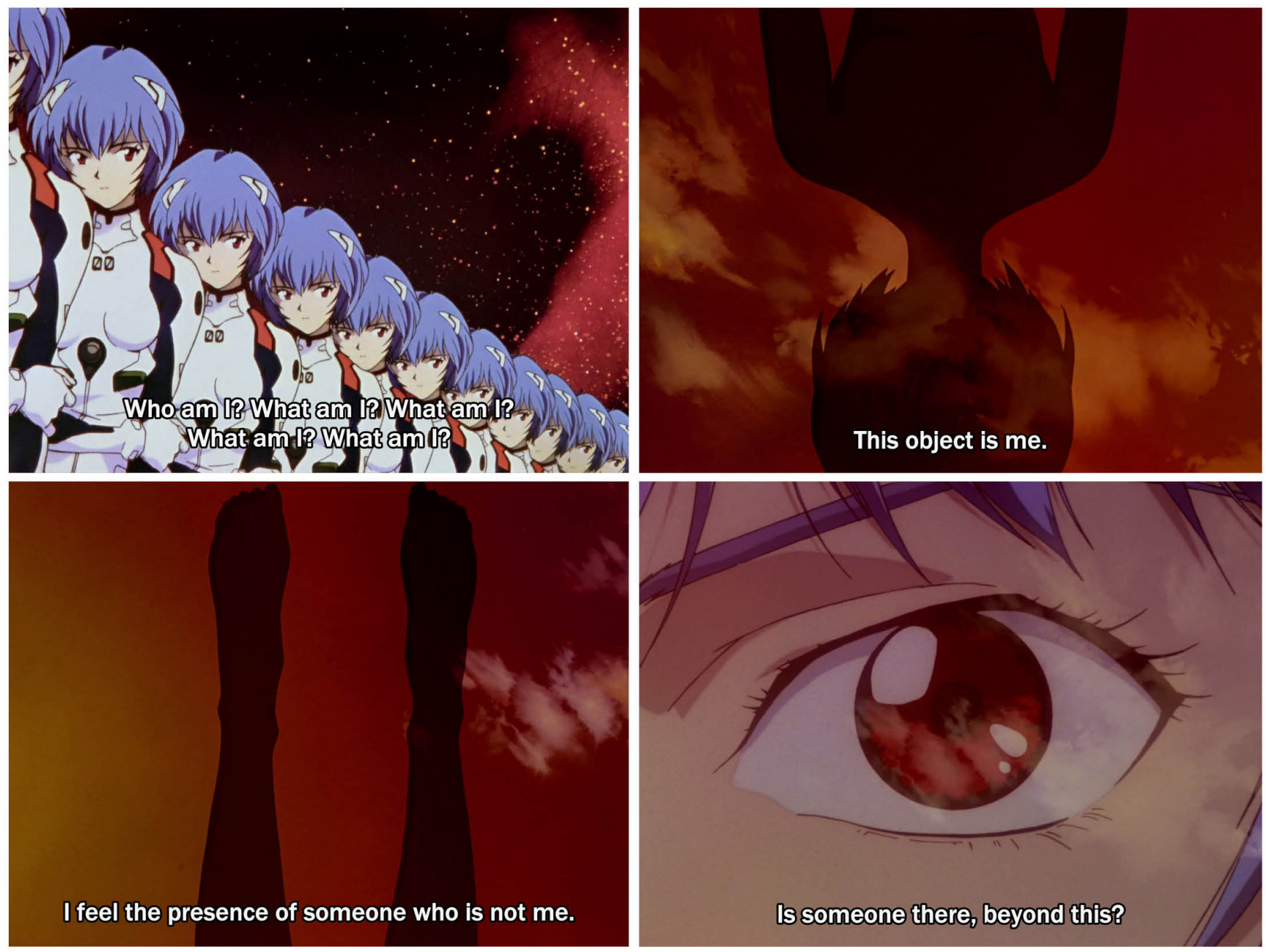

Figure 5.2. Rei's monologue about her selfhood in episode 14 . Her characteristic (lack of) expression shown on the top left. () khara, inc. acting works, as there are always elements of other characters in/on the character. In a way, her declaration that she is "a vessel for a soul" is somewhat accurate: her body contains (or rather, has on its surface) the codes of others. Interestingly, Rei's reliance on relations and linkages is directly expressed, as when she is asked in episode 6 why she pilots the Eva unit, and she responds by saying "kizuna," or "bonds." The word kizuna contains elements of emotional ties, of relationship 
and connection and linkage, which is precisely how figurative acting must operate: it fundamentally cannot function without those linkages to others.

For Rei, these linkages can even be considered as going beyond the EVA series. Crucially, this is due to Rei's particularity, which has made her, perhaps more than any other character, a fan favorite that is repeated not just in merchandise, but in variations of characters like her in other anime. She even spawned an entire character type (sometimes labelled as küdere by fans) that is extremely reserved, sometimes cold and often not technically human, such as the robot Yuki Nagato from The Melancholy of Harubi Suzumiya. What marks Rei's character in EVA is not necessarily her particular expressions, but actually her lack of a variety of expressions. It is as if she does not perform many figurative codes at all, in stark contrast to the hot-headed Asuka and the boisterous but concerned Misato. This absence of expressive variety goes hand in hand with the 'hyperlimited animation' of EVA: Rei hardly switches codes, barely moving at all.

Such operations further evince the dynamics of figurative acting: the absence of expressions itself actually developing into a type of expression (especially as it is repeated in other characters). Performing objecthood through figurative acting can be seen as working similarly: Rei is both highly specific and yet herself becoming another object for other objects. Yet such an interrelation does not mean she has no capacity to act and induce effects. In fact, Rei regularly operates according to her own volition in the series, even against her orders, including when she sacrifices herself in episode I9, disobeying Gendō in EoE or any number of times she aides Shinji in his introspective moments. Additionally, her character patterns become the template that restricts later character repetitions into Rei's range (or lack) of expressions. Rei also exemplifies the more radical possibilities of objecthood, which becomes especially apparent in the finale of the TV series, episode 26. For there is no other episode in which Rei's particularity and its limits are brought to the fore in such a stark manner. 


\section{Moving into Objecthood}

Before directly addressing the TV series ending, it is important to reiterate that embodied acting and figurative acting are involved with each other; similar to the human-like non-humans (Eva-or, moving through embodied acting as an active object) and the non-human-like humans (Rei, a figurative actor who is both a copy of and made of others). Like depth and surface, the two can appear separate, but are actually interrelated. At their absolute extreme-that is, impossible in actual enactment as there will always be something of the embodied in the figurative and the figurative in the embodied—embodied acting is so interiorized it is all depth, so singular it is isolated; figurative acting is so externalized it is all surface, so codependent it is rigidly repetitive. Figurative acting is restrictive as it is reliant on repeated codes and must stringently reinforce them in relation to earlier instances; the individualism of embodied acting can bring with it a liberation from such restriction, but it can also be isolating and walls off the boundaries of the self with a strict separation.

As EVA explores the extremes of these performances in non-human and human objects, it exposes their interrelation by inverting the modern dynamic. In some sense (as already mentioned above), it is as if the series attempts to flesh out interiority in the characters of figurative acting. However, humans become objects, and Eva units are somehow haunted by humans, as Eva-oI is with Yui Ikari. EVA pulls on both threads to show how they loop into each other. The tension between interiority (indicative of embodied individualism) and figurative acting (where each character is composed through the relations to other characters on their surface) is further revealed through the incursion of other characters in their minds: there is almost always another character there, either speaking or acting or viewing, even if the other character is another version of the character whose interiority is shown as they break one layer of surface to move into another surface layer.

This dynamic of interrelation is grappled with in the final episodes as they move through the most focused and explicit examination 
of selfhood in the TV series, delving into the interior of the main characters. For example, episode 26 shifts rapidly between abstract, metamorphic images and partialized elements of Shinji (his voice, his facial expression). This covers the extreme tendencies of both modes of acting: on the extreme of embodied acting, the bodies swerve and morph into different shapes, as if enduring meaningless transformations that are so individualized, they cannot be understood; for figurative acting there are abstract symbols that are not repeated (like the outline of fish), making them singular symbols that are unintelligible in this context.

Throughout this sequence, in the voice-over dialogue, the characters seem to guide Shinji toward an understanding of the necessity of others for the formation of self. Occasionally, Shinji follows, seeing the faults in individualism, at one point even claiming in exasperation: "If I'm alone, I'll always be alone, no matter how far I go with it! The whole world is just me!" In these sequences, there is a display of both abstract embodied acting and figurative acting, as if Shinji's turmoil is explicated in the rapid switching between the extremes of the two modes of acting: extreme metamorphosis that displays unreadable emotion due to hyper-individuality; and disparate parts that constitute a self completely divorced from the body. The latter tendency (that of figurative performance) is exemplified in the moments when Shinji transforms into only his facial expression, which takes over the whole screen. In this display, it becomes obvious that facial codes are themselves able to function as objects, as Shinji has now become the code, just as the codes had constituted him. Such a sequence seems to directly visualize what Morton describes as a "whole that is less than the sum of its parts," "a whole that subscends into its parts," extending outwards and inwards at once. But this is not necessarily a smooth or easy process of realization, especially coming from the position of a modern human individual:

As one becomes aware of more dimensions of oneself, that one is not in fact one nor dissolved into multiplicity, but haunted by spectral parts 
of oneself that are also not parts, that subscendently wiggle around all by themselves, one might go crazy. (2017: I60)

Indeed, the fear of the self completely disaggregating into parts lies at the edge of figurative acting, and the brink of madness is always threatening to seep through in these scenes, as it does throughout the series and films.

Ultimately, the torrent of imagery and Shinji's dialogue seem to move to the side of figurative acting, toward objecthood. But in a strange way, this recognition and acceptance of an object-oriented selfhood occurs through engagement with embodied acting and the individual's insistence on depth, only to realize that the depth returns us to the surface: Shinji's insistence on his individuality is accompanied by the crude image of a human that seems to be endlessly repeated as it zooms in on itself, like a fractal, before Shinji morphs into the parts of his face, followed by the other characters refuting his claims regarding individualism (Fig. 5.3). It is as if, in an effort to reconcile the tensions between surface and depth, figurative and embodied, there was a brief attempt to think of a different kind of depth, a fractal type of depth that seems to constantly rise up into itself even as we descend downwards.

It is important to note the dialogue at this moment, spoken by different female characters: "By recognizing the differences between yourself and others, you shape who you are. The very first other person is your mother. Your mother is a person separate from you." Significantly, this segment raises the point of a person's relationship to their mother, a topic often ignored by (sexist) conceptions of individualism because it radically undermines the strict inside/outside and self/ other divisions presupposed by individualism (see Morton 20I7: 2). Instead, one person is born from another person, literally originating from inside another, dependent on the (female) other, yet somehow distinct. This is reflected in the next lines, where Shinji states, "Right, I'm me. But it's also certain that the other people shape my mind 

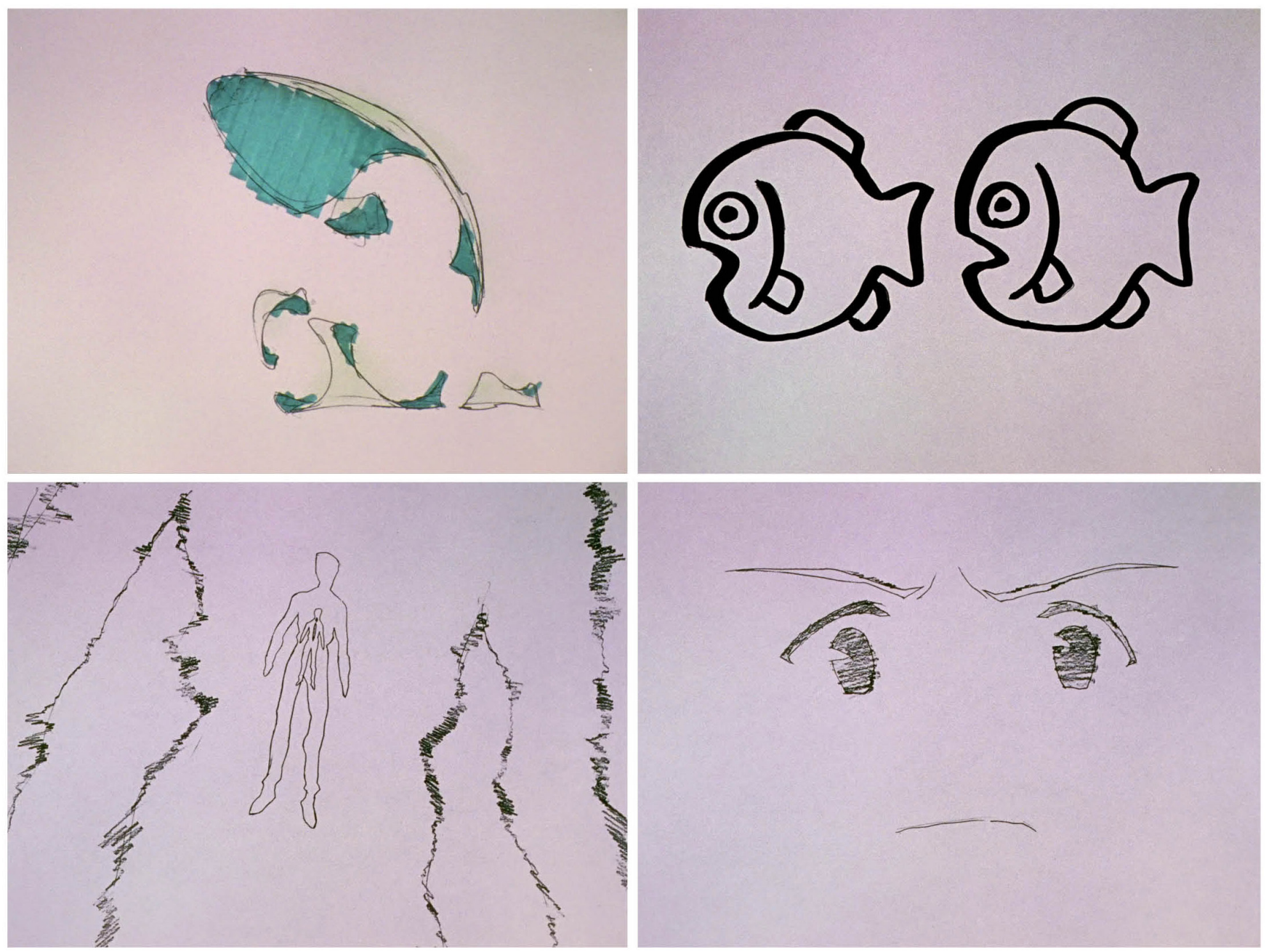

(kokoro) as well." What finally results from these exchanges is a sense of figurative acting which affords an organization of a selfhood that is constituted by its connection to others, but one which does not deny itself its particularity: Shinji is a character who is distinct from the others, even as those others are also part of what constitutes him. After this sequence, Asuka exclaims that Shinji finally understands,

Figure 5.3. Shinji's movement through abstract embodied acting (top left), strange symbols (top right), moving through a fractal image of the human (bottom left) and his subsequent subsendence into parts (bottom right). () khara, inc. and the scene suddenly switches back to fully colored animated imagery, 
entering an 'alternative everyday' world, with the characters playing different roles. This section of the episode explores the transformative capacities of a selfhood where Shinji, along with many of the other characters, are slightly different in their personality. However, the standout example is Rei, here imagined as a completely different character type (loud and unorganized as opposed to quiet and reserved) (Fig.5.4). Such a version should not be a shock as there are examples of multiple Rei's throughout the series, even a scene of a large vat of Rei clones in episode 23, each of them smiling (which the 'regular' Rei usually does not). Yet this version of Rei can be taken as a violation of her character (even in merchandise, she is only rarely seen without her somber and forlorn look), implying the modern perspective of the individual, where she is closed-off and defined in that original personality, making such a contrast a betrayal to her 'true self.'

However, read through the tone of the later parts of the episode and the silliness of the scene, this can be interpreted as playfully displaying the radical lack of closure in figurative acting-and subsequently for selfhood as objecthood-whereby the character is not locked into place, but always has the potential for change. This occurs even when we think a certain combination of codes becomes heavily associated with a character, repeated with such frequency (or their clear absence) that they appear as their personality, as in the case of Rei and her somber look (and lack of smiles). But as figurative acting is maintained by certain codes, and each code is linked to other iterations of that code, it is also haunted by the possibilities of other codes. Each code thus subscends into other codes. As Morton notes, subscendence would actually allow for emotional registers to have, on some level, elements of emotions that are traditionally not supposed to be there. In anger, we may see elements of hesitation, grief or even humor (Morton 2017: I04). In this sense, there will always be the potential for a radical shift in character through the execution of figurative codes, something which is constantly enacted in anime as characters switch between emotional registers rapidly. 

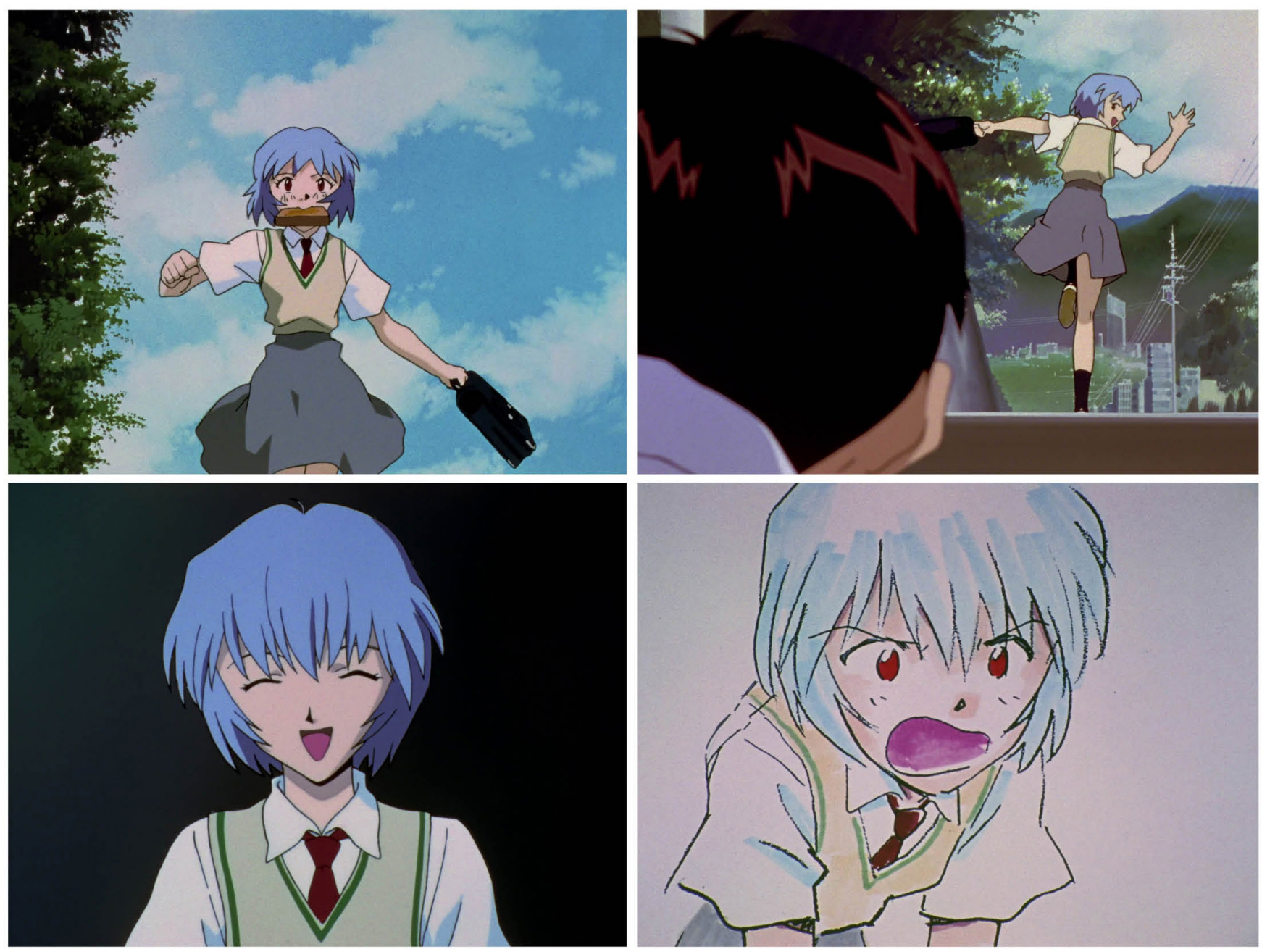

Rei as a character produced by such codes is emphasized here in the 'alternative everyday' by the fact that her general design is the same (although, significantly her costume is different, with an added vest on her uniform), but she performs certain figurative codes that are, for lack of a better phrase, uncharacteristic of her previous character: specifically the running with bread in her mouth (a common code for lateness and sloppiness), arched-eyes and cheery smile during her

Figure 5.4. Rei's display of uncharacteristic figurative acting codes for her character in episode 26. (C) khara, inc. 
introduction to the class and an explosively angry face when she accuses Shinji at the end of the sequence. These produce a different character by their combination, emphasizing that the design can remain the same, but the specific aggregation of codes marks a shift. As such, a starkly different particularity is created for the 'alternative everyday' version of Rei's character, highlighting one of the ambiguities at the heart of figurative acting: Is the character producing the expressions, or are the codes producing the character? Furthermore, why should this version not be considered as another addition to Rei's cumulative combination of codes?

While the change is sudden, rapid switches to different emotional registers are featured constantly in anime (even in EVA, as in Misato switching from joyful to scolding in episode $\mathrm{I}$ ). Yet, in the case of Rei, there is no narrative justification, where different emotional codes are slowly accumulated to prepare for a shift in character. Moreover, the change is not just one or two different expressions, but appears comprehensive, a complete transformation in character type, jarring in comparison to the earlier version of Rei (who exhibited her normal register just moments before in the episode), as if it were an all-too-abrupt violation of her perceived totality as an individual character. In consideration of this, Rei's stark change can be seen as approaching a limit of particularity, and exposing a continued reliance on the framework of individualized characters, even in anime. The performance of Rei, then, might not be so much a betrayal or violation, but rather an example of the potential for both particularity and radical change, even in a mode of performance that relies on repetition; at the same time, it displays the limits of a self that is constituted by figurative acting, which cannot completely subsume any individualizing tendencies.

After these scenes with Rei, Shinji reflects on the events and says, "This is also a possible world. One possibility that's in me. The me right now is not exactly who I am. All sorts of me's are possible.” This 
leads to Shinji's revelation of a greater acceptance of himself, and in the last moments of the episode, Shinji makes a literal breakthrough: He shatters the world around him, which is whirled away for him to be greeted by the entire central cast congratulating him, the last image of the series featuring Shinji performing the widely used figurative code for smiling with arched eyes. There is an optimism in these final segments and a sense of solidarity among those shown as they congratulate Shinji, to which he responds with thanks. Shinji's revelation can be interpreted as an alignment with the tendency toward objecthood (even for humans), a particularity of self that is gained through the specific combination of other codes (or objects) that exist both outside and inside him. This is directly revealed in Shinji's acceptance of his own selfhood and the congratulations of the others that surround him, somehow, in terms of the diegesis, existing both on the inside of Shinji and, visually, on the outside of him.

In this sense, the final sequences land closer to the operations of figurative acting, embracing a sense of interrelated selfhood, where Shinji is, like Rei, something like an active object made of other objects, where the classically conceived borders of inside and outside of individualism do not operate quite the same way. As such, the TV series ending concludes with an optimistic affirmation of objecthood that reveals the potentials of the performance of anime's media-form: anime broadly and EVA in particular invoke a general tendency toward (inclusive) objecthood that had been obscured by modern individualism, a blurring of the line between internal and external, human and non-human entities (objects), a mode of existence which may hold ecologically positive potentials.

\section{Styling Selfhood with Objects}

Historically, EVA overlaps with the general sense of crisis that is often attributed to the 'lost decade' for Japan in the I990s, when the 
economic bubble burst, leading to the restructuring of society, the Aum Shinrikyō terrorist attack and the Kobe earthquake, among other events (Maejima 20IO: 3 I-33; Uno 2008: I7-2I). However, one might also see this as a more general crisis of the modern human in post-modernity, which extends beyond Japan to a more global reach (which EVA itself did, even during its initial release), one which is most prominently apparent in consumer practices in varying ways.

Among the explosions of niche consumer products and their corresponding consumer categories that (continued to) take hold in the I990s are late-night (shinya) anime, their surrounding media mix products and the visibility of the otaku who consume them. EVA is noted by commentators such as Satoshi Maejima as integral to the popularizing of anime for that late-night time-slot, and it is these latenight anime that are correlated with otaku fans who admit strong feelings for anime (and other media and merchandise) objects. Such objects are often anime characters of a certain type that are materialized in various media, whether it be an anime, manga, game and/or figurine. But what links these different products, despite their differences in material and medium, are often character designs and figurative acting codes that help animate the inert materials through the codified poses, each imbued with what Marc Steinberg calls "dynamic immobility" (Steinberg 2012: 6).

It is important to stress that these various figurative acting codes (or object-parts) are also utilized in fan production and imply a dispersal of agency that is seen throughout figurative acting: while the otaku can direct a character in different directions than the source works by introducing new codes, the codes must be enacted by the otaku, meaning that the otaku must ultimately work within a certain register to maintain recognizability. Moreover, though there is some tendency to maintain a certain degree of similarity to the character in the source works, deviations like the 'alternative everyday' Rei version are also 
very common, performed by utilizing various other figurative acting codes; subsequently, it becomes unclear if it is actually the human actor or the object-parts of figurative codes or the character itself which become the central locus of agency-that is to say, there is a distribution of agency in the production of derivative works by otaku.

In consideration of this, what Azuma calls database consumption of moe-elements (which can be extended to figurative acting codes and other object-parts) might be reimagined as otaku overtly engaging with the various object-parts that constitute the objecthood of a specific character; characters can not only be broken down into parts, but are constituted from them-they are wholes less than the sum of their parts, they subscend themselves, and otaku openly engage with this in their cultural activities. This type of database consumptionproduction evinces an overt engagement with objects, especially as anime characters themselves are sold as physical merchandise.

Consequently, otaku consumption often appears as a type of literalized commodity fetishism that is derided. Indeed, otaku are generally regarded as 'strange' because they let these anime objects affect them so much, let themselves engage with them in a manner deemed excessive. Perhaps it is the characters' human-like figure which makes it too obvious that there is activity, if not an agency, of objects involved here, in part causing a negative reaction by non-otaku as it violates the modern order of human subjects controlling passive objects. In some senses, this violation might be seen as the focus of much of the literature on otaku around the turn of the 2 Ist century, which seemed to hone in on otaku as the new vanguard of the post-modern subject (e.g., Azuma 2009). Indeed, the type of otaku consumption-production involving moe-elements can be seen as an emblem of a contemporary (post-modern) mode of existence, one where objects are increasingly relied upon in practices of fashioning selfhood for humans.

This includes the concurrent performances of a 'lifestyle' that increases in visibility during EVA's initial broadcast in the mid-I990s and 
continues to be a globally dominant mode of expressing selfhood. Beyond otaku practice (which may itself be conceived of as a type of 'lifestyle'), this is perhaps most visible in the realm of fashion, where certain clothes, housewares, architecture, restaurants and cafes, and music, among other objects, establish a certain 'style' of living. Gabriella Lukács (20I0) sees lifestyle as coming into prominence in Japan in the I990s as neoliberalism continued to widen its spread, and is evident in the shifts in the era's media. In particular, Lukács points to the rising number of live-action 'trendy dramas' that depict certain lifestyles and their connection to the growth of niche consumer marketing. Lukács notes that lifestyle is premised on the idea of choice, of personal, individual selection, which plays out the neoliberal fantasy of a discrete self, disconnected from the external social world, who acts freely in the market-you express your individualism through the purchase and usage of certain products (if you can afford them), employed in your personal combination of such commodities, regardless of economic station (i.e., social class). In some senses, this may appear empowering and liberating, enabling someone to break constraining, even oppressive cultural categories in the effort to reinvent a selfhood that feels comfortable and appropriate for them as an individual.

At the same time, this endorsement of constant flux overlaps with an idea of autonomy premised on selection of consumer goods, which works well for sustaining a constant flow of new products to consume as trends ebb and flow. People are regularly incited to (re)define themselves, finding 'who they truly are' by exercising their self-determination through consumption of these new (and ultimately disposable) commodities-they are always in the process of becoming their self through styling their life with the most recently trending objects. These objects are mass-produced commodities, connected to a large array of branding techniques and images, all of which are carried with the objects as they become included in the person's selfhood. 
Explicitly external to the human person, they are somehow meant to be expressions of our internal individuality.

In this sense, there is a similarity to the operations of figurative acting in the performance of lifestyle: using external objects to constitute a sense of self. In addition, just as each performance of a figurative code becomes the site of citation for further iterations, a person may even begin to embody a certain type of lifestyle that becomes the model for others to style their own lives on, and the cycle continues as a new trend catches on. Here, we find a strange double-bind for performing selfhood under neoliberalism: while styling the self appears to activate a type of individualized agency as one chooses their products, that person also becomes an object of consumption, creating not just products for consumption, but a selfhood that is consumable as recognizably in (or against) trend. Ultimately, there is a tension between these two dynamics: individualism in expression, only to be turned into an object in the process (Diederichsen 20I2).

Although lifestyle performance is not an explicit endorsement of neoliberalism and more an example of how integrated into daily life neoliberalism has become, it is important to note the underlying political underpinnings of performances of selfhood. More to the point, this politics of performing selfhood has gained a new layer of relevance as taken up in contemporary ecological theory. In fact, Morton sees the neoliberal sense of individualism as inherently destructive (for humans and non-humans), but sees ecological potential in the relationship to consumer objects (20I7). The latter mode (lifestyle performance of selfhood via consumer objects) is ecological in the sense that the lifestyle performer implicitly acknowledges their relationship to non-human objects, their interdependence on them.

For Morton (although he does not name it precisely), lifestyle performance can also be seen as a 'chasing of the self' to find that there is something else there, the non-human objects with which you define your selfhood: "As we style ourselves according to our products and 
our thingies, something else is happening. We are being styled by them" (2017: I38). This is "an aesthetic mode of relation. And it's about allowing that thing to relate to us" (ibid.). Morton cautiously sees consumer fetishism and lifestyle performance as something that might be moved into (or in his terms, "underneath") as it is "a distorted actuality," and one of the few places in our contemporary culture where objects are included in social space, and thus in some senses ecological because we acknowledge and accept their inclusion (2017: 69).

This is crucial for Morton because this type of selfhood not only allows for a very different sense of conceiving of the human self, but of the idea of groups, of inside and outside borders, and of relating to the (hyper)object of global warming (2013). According to Morton, if we think of humans as the only agential actors, then the changing climate and the pollution cannot appear to affect us, because they are seen as non-active objects. However, if objects are not just part of us, but necessary for our production of selfhood, then we are more open to recognizing that 'I' am not an isolated human individual, but rather am made up of a plethora of other human and non-human objects, from bacteria to language, from evolutionary products from other creatures (human lungs having evolved from fish) to clothes. When considering this, one can also understand how these non-human objects are part of that person, affecting them in fundamental ways, just as global warming is active upon us. This destructive (hyper)object is not something out there, but inside people (in the lungs that breathe in pollution; the food we eat), on and around people (as in clothing, which can link to environmentally destructive production processes), with people at all times. Moreover, this is not only a personal or even local problem, but also concurrently a global one. According to Morton, the next step is "acknowledging this always-already quality of nonhuman impingement, and bringing that awareness, which is not the opposite of action but rather a quantum of action . . . into actions at other scales" (2017: I39). 
Yet, despite this potential, the movement toward acknowledgment of the non-human brought into action at larger scales is no easy or simple task-although there are some 'ecologically oriented lifestyles,' indications that lifestyle performance is directly relating to any large-scale shifts in tackling global warming, pollution and environmental destruction is minimal. Perhaps the difficulty of moving to a larger scale is due to how lifestyle, despite operating in a similar manner to figurative acting with regard to objects, is marred by a strong tendency toward (neoliberal) individualism and its affinity for endless, disposable consumption, which has clear, damaging ecological effects especially as it scales up. But engagement with the scales necessary for ecological action is obstructed by the central unit of neoliberalism: the individual. Significantly, it is precisely an examination of individualism and scale that is central to EVA's narrative of a chosen child-pilot who must save the world. It is this connection of the individual to the global that becomes the focus of the filmic ending of $E o E$, where the examination of selfhood shifts toward exploring the destructive tendencies of individualism and its direct relation to planetary scale devastation.

\section{Ecologically Destructive Individualism}

As episode 26 presents a literal exposition of the 'chasing of the self' and lands with a heavy lean toward objecthood and a subscendence into parts, the TV ending can be read as embracing a more ecologically oriented mode of existence. However, the joyous optimism of the TV anime's ending was rejected by many viewers of the show all over the world. Despite the wide involvement of objects in lifestyles, even otaku, who can be seen as openly engaging with objects, were upset by the TV anime's ending, ironically admitting to how much an object (in this case the anime series) can affect them, but also revealing how ingrained and resilient modern, anthropocentric thought is, even in such communities. 
In the aftermath of such reactions, instead of re-emphasizing the objecthood embraced in episode 26, the final film EoE presents a radical break from the TV ending, especially as regards the type of selfhood that is enacted and explored. Interestingly, this break is revealed through the impression of a continuity of narrative (which takes place after TV episode 24, skipping over episodes 25 and 26) and of the character of Shinji: unlike the jarring shift of somber Rei to an unorganized, loud character in episode 26 , Shinji is supposedly the same as he was in the TV series, as if a 'rounded' (though disturbed and depressed) character. However, the ecologically oriented objecthood potentials of the TV ending are eschewed in favor of pursuing Shinji's selfhood as an individual. The result is not the movement from individualism into objecthood as in the TV ending, but rather a staging of the choice between two different types of individualism in EoE. Moreover, what can be read in this division is an ecological politics about the stakes of embracing the tendencies of (neoliberal) individualism when performing selfhood.

Regarding the reasons for the divergence between the two endings, it is difficult to provide a definitive answer. In some ways, the filmic ending of EVA can be seen as a direct response to the negative reception of the TV series ending (and subsequent rejection of the objecthood episode 26 lands on) in EoE's stark difference in tone and content, literally ending the world. Apocalyptic scenarios (from global warming to various doomsday cults) were prevalent in Japan and around the world at the time, but the large-scale extinction of life in the finale also recalls that of the much earlier anime Space Runaway Ideon. A concrete answer is difficult to provide from the staff as well, as anime production is incredibly complex, with multiple layers of decision-making that are beyond the singular vision of a director, wri-

7. For a more detailed breakdown of anime production and its dispersal of agency, see Suan (20I8). ter or producer, even occurring across national boundaries (parts of EVA even involved Korean and Chinese animators and cel-painters). ${ }^{7}$ However, irrespective of the reason, the sharp shift in tone-from 
playfulness and optimism to grotesque visions of catastrophe-does allow for a comparative interpretation where the two endings each provide differing views on the respective tendencies of performing selfhood they explore.

Thus, read in relief of each other as an examination of the two extremes of performing selfhood (i.e., objecthood and individualism), the two endings reveal what is at stake, ecologically, in each type of selfhood. The TV series ending might be able to sustain an interpretation as ecologically oriented in its embrace of the inclusion of other objects (especially with regard to Morton's views on a potential for scaling up a 'quantum of action'); but, as noted above, under neoliberalism even some of the more object-accepting performances of selfhood in lifestyle contain a latent tendency of anthropocentric individualism that reaches an impasse for acting ecologically. This is what the filmic ending brings to the fore as it reveals the ecological dangers of the other extreme of selfhood performance: exposing the explosive, planetary-scale destructiveness of (neoliberal) individualism.

To begin, it is worthwhile comparing the type of acting in the filmic ending to the TV series. As anime characters-in terms of their 'soulful body' design and enactment of figurative acting codes-every (human) actor in (TV and filmic) EVA is constituted through the tendencies of figurative acting. But instead of moving through individualism into objecthood (or embodied performance into figurative performance) as in the TV ending, EoE moves away from the figurative acting tendency toward interrelated objects, to the individualism in the extreme of embodied performance. Indeed, the film concludes in a spectacle-oriented fashion, including phenomenal embodied performances of/in animation. For example, there is the fight sequence between Asuka and the mass production Eva units, by key animators Mitsuo Iso and Yoshinari Yoh (Fig.5.5). Asuka's Eva unit in particular is important, because it operates with such lucidity that it seems almost human, intentional in its operations. The movements feel hefty, bodies 

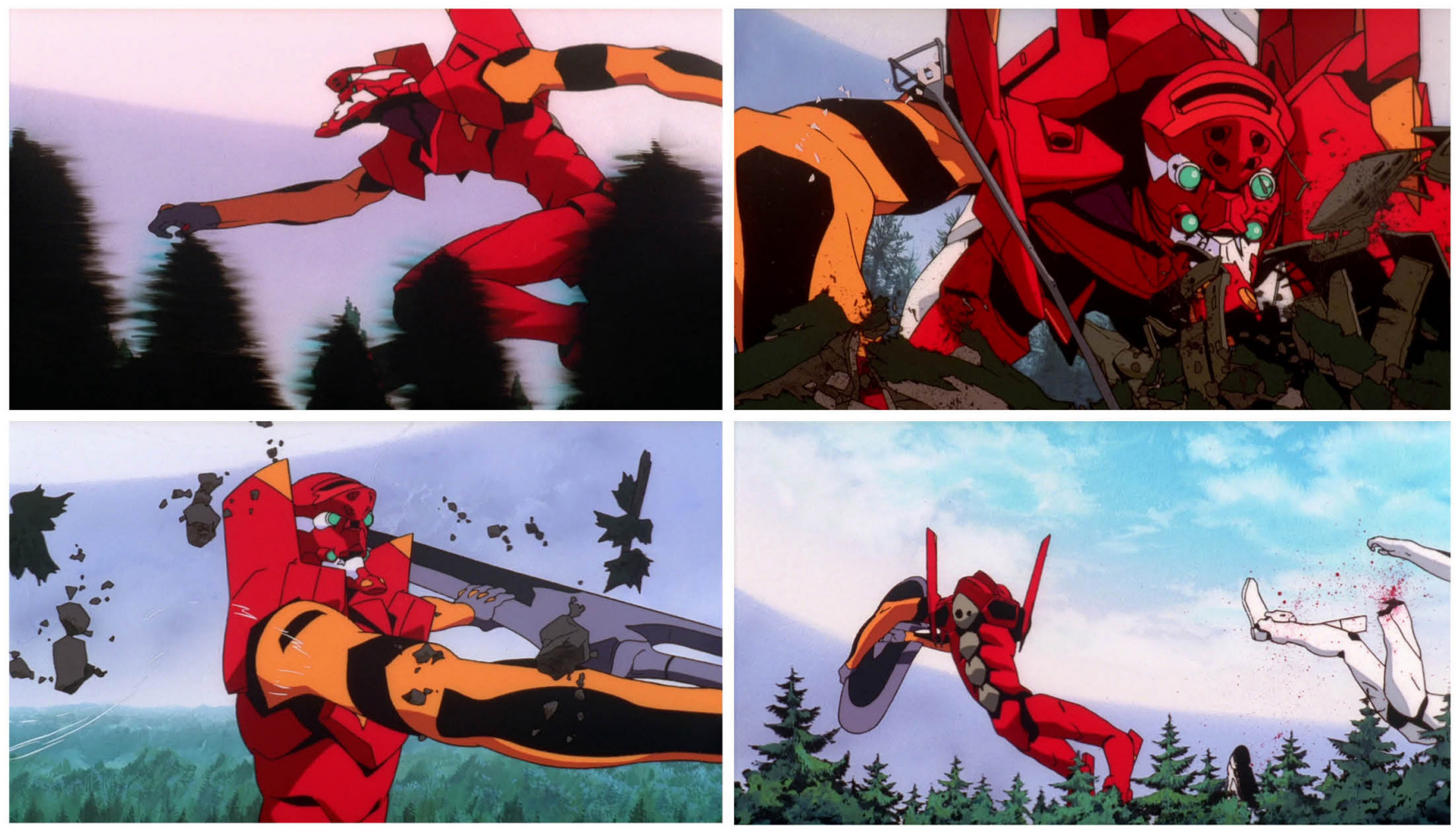

Figure 5.5. Asuka's adept piloting of her Eva-unit in End of EVA, displaying weighty movements through embodied acting. (C) khara, inc. clashing as they wield heavy objects. Each action evinces the weight of the swings, of their blowbacks, a sloppiness to the grappling that results in broken and severed limbs; a viciously efficient dance of executions as Asuka struggles against the other Eva units while she runs out the clock on her Eva unit's on-board energy. But unlike the scene in episode I9 where Eva-or goes berserk, here her unit stops when it runs out of energy, and the embodied performance evinces Asuka's deftness in operating (controlling) the non-human Eva-02 unit (albeit only after she accepts its idiosyncrasies as an object with some connection to her mother-another instance of the human haunting the non-human Eva unit).

The above-described embodied performance is one of the stand-out scenes of the film, and a preview of the focus on human individualism 
that defines the filmic ending. As distinct from the TV ending, instead of the helpful guidance of others in Shinji's mind, in EoE when we delve into the depths of Shinji's interior to find others, the potential horror (from the perspective of individualism) of figurative acting in the idea of other things inside of an individual is exposed, and in the process, moves toward the tendencies of individualism. This is succinctly displayed in the sequences of Asuka and Shinji in Misato's apartment, images which are part of Shinji's psyche visualized. In contrast to the lighter domestic scenes of the TV series ending, Asuka is aggressive, berating Shinji. Such hostility elicits a violent response from Shinji, who chokes Asuka, and spirals into his expression of feelings of complete isolation. Images of the other characters flash across the screen at dizzying speeds, accompanied by a torrent of many random, sometimes abstract, images. In addition, many of the scenes of lush, complex animation feature grotesque, confusing imagery, such as the mutating Eva units. The attempt to produce individualism despite anime's reliance on codified expressions seems to slip into the extreme separation of individualism on the one hand, or resort to codes that no one will understand on the other. This illegibility in some senses applies to the entire film itself, which features so much surreal imagery that it is almost impossible to decipher through traditional techniques.

In some ways, this does resemble the strategies and imagery of the TV ending, but in EoE a different spatial organization arises: the division between internal and external. This inside/outside separation is not present in the TV series ending, where the diegesis stays resolutely inside of Shinji to have him subscend into various parts and then get reconstituted, in the process disclosing and emphasizing the interrelated operations of figurative acting. In contrast, in the sequences of EoE where we delve into Shinji's psyche, the separation between internal mental state and external world operates closer to the spatial dynamics of embodied acting's individualism: the interior is the source of actions that have effects on the external world. 
We frequently switch between Shinji's interior state and the exterior events, with constant reference to Shinji's internal decisions affecting the rest of the world. Although Shinji did not instigate these events directly (Gendō and/or SEELE appear to orchestrate and/or intervene behind the scenes), the fate of the world seems to fall on Shinji's shoulders. At one point, Gendō's confidant Kōzō Fuyutsuki even states, "the future is up to Ikari's son [Shinji]," emphasizing the internal struggle of Shinji and its effects on the external world, but also the thematic of personal, individualized responsibility. Shinji is literally closed off from the world, the fate of which rests on his mental state and his subsequent decisions based on that. Eventually, Shinji's feelings of isolation and unhappiness transition into scenes of the literal dissolution of all the other characters into liquid, the result of Gendō and/or SEELE's initiation of the Human Instrumentality Project. All of humanity is merged in this liquid state, which is presented as the final goal of the Human Instrumentality Project, seen by SEELE as the final configuration of humanity, worth all the destruction to initiate. Shinji is shown interconnected with Rei in this amber 'soup of life' (the 'sea of LCL') to quell Shinji's fears of rejection and emotional pain, and here Shinji is given the chance to stay in this state or not. What is featured, then, is a similar crisis of self as in the TV series ending, but here Shinji is presented with a distinctive set of choices to make on his own: to maintain the complete breakdown of barriers where all people are merged into one, or to raise those barriers completely.

Such a selection between these two poles might be described, in the words of Christophe Thouny (albeit with different concerns and not in reference to this particular sequence), as "the two sides of a modern social structure that relies on the production of individual subjects forced to occupy an agonistic position: that of having to navigate between the two dangers of a complete isolation of the self from the social collectivity in a movement of infinite fragmentation and of both the fusion and dissolution of the self" (Thouny 2009: I I4-I I 5). This 
latter option (fusion and dissolution of the self) becomes literal for Shinji in 'the sea of LCL' where all barriers between people are erased, and the former (isolation) can be seen in the reinstatement of boundaries between people. Moreover, Thouny's description draws attention to how, despite the apparent visualization of a fully merged and dissolved self, the choice with which Shinji is faced can be read as still operating within the bounds of modern, individualistic selfhoodthat is, Shinji must actually choose between two different types of individualism: an individualism of isolation or an individualism of a singular (but merged) whole.

Such a choice between individualisms also recalls Morton's conceptions of contrasting ideas of holism and their relationships to individuals. What was discussed above as objecthood would correlate with what Morton calls "implosive holism" (the whole subscends into its parts; the whole is less than the sum of its parts). But this is only one version of holism. According to Morton, individualisms can be conceived as different types of "explosive holism," whereby the whole is seen as greater and/or more real than the sum of its parts. Morton further explains that there are variances to explosive holism, describing them in three positions: (I) "the whole is more real than the parts"; (2) "the whole is greater than the parts"; and (3) "the whole is less real than the parts."

For Morton, the first and second explosive holisms can easily slip into each other and indeed, this is evident in the result of the Human Instrumental Project in EoE (the completely dissolved selves in the 'sea of LCL'): the first position-the whole is more real than its parts (the final configuration of humanity) - easily extends into the second positionthe whole is greater than its parts (it is most important that all humanity merge into this final configuration). The third position (the whole is less real than the parts) Morton connects to neoliberalism, its valorization of the individual at the expense of the whole: "There is no such thing as society [only individuals]," as Margaret Thatcher, proponent 


\section{WHOLE IS MORE REAL THAN PARTS}

\section{WHOLE IS GREATER THAN PARTS}

Humanity's final configuration $\leftarrow$ Human Instrumentality Project $\rightarrow$ Importance of merged configuration

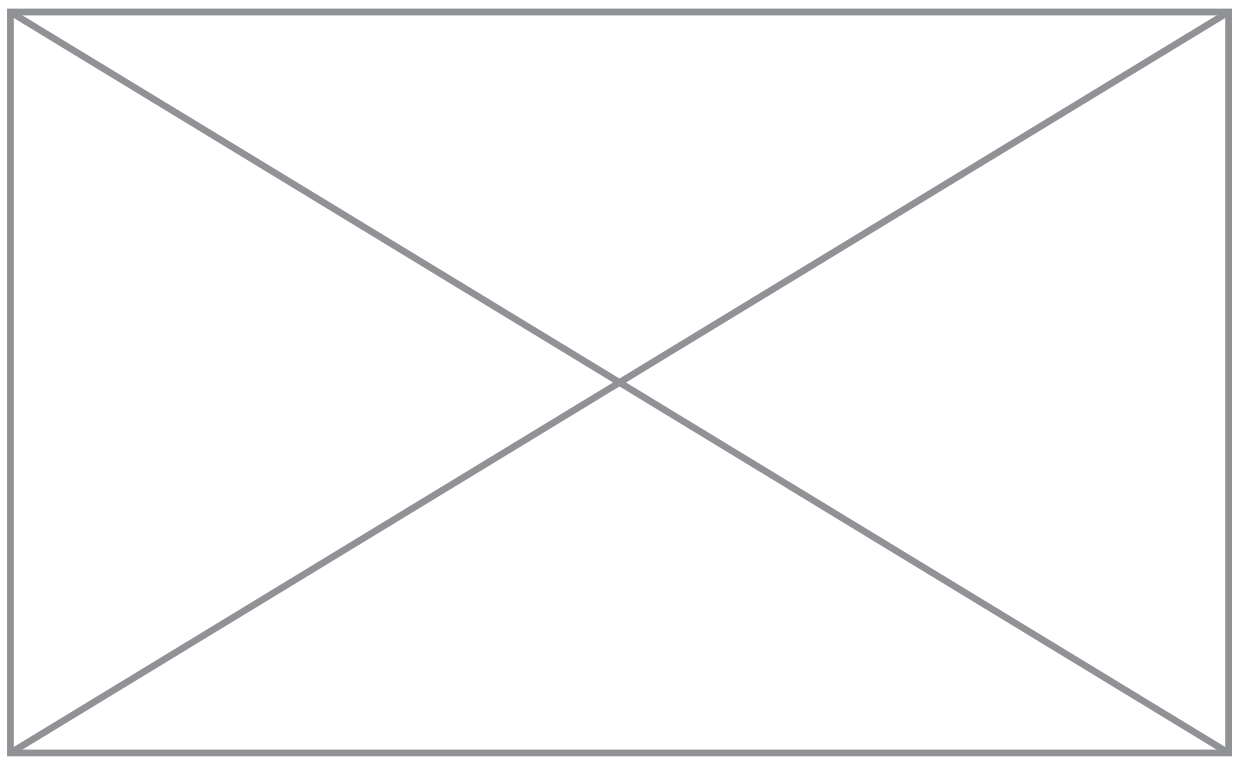

End of EVA:

Humans merged

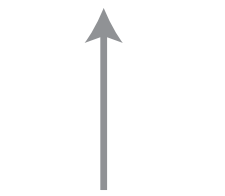

Shinji's choice

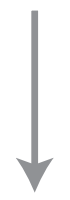

Objecthood

4. WHOLE IS LESS THAN PARTS

3. WHOLE IS LESS REAL THAN PARTS

Figure 5.6. An adapted version of Morton's logic square of explosive and implosive holism, depicting the choice between individualisms that Shinji must make in End of EVA: either choose between the first and second positions' merging of humanity or the third position's individual borders (Morton 20I 7: I07). License: CC BY 4.0. of neoliberalism, famously said (2017: I07). This is the direction that Shinji moves toward in the EoE, choosing to maintain individuality, to prop up borders around people (the third position), instead of dissolving one another into a soupy mass of humanity's merging (the slippage between the first and second positions) (Fig.5.6).

Thus, in EoE, there are only the varying options of explosive holism from which Shinji must choose. Gone is the subscendence into various parts. Instead, there is an attempt at working through individualism, specifically at keeping up the borders between people. For Morton, these explosive holisms are dangerous and ecologically destructive. 
They allow for either the replacement of some cog in a larger machine ("let that species die, another will take its place"), because the whole (the ecosystem) is greater or more real than the parts (positions I and 2); or it draws lines around things in advance (the human individual and its inside/outside borders) and actively operates on the non-human outside that border, ignoring the larger effects because the whole is less real (position 3). These are ecologically devastating concepts and, indeed, the former (positions I and 2: the whole is greater than and/or more real than its parts) in EVA (SEELE) end up with complete evisceration of the Earth. Even Shinji's choice to seemingly end or 'reverse' the end of the world by choosing individualism still leaves us on a dead Earth. In this way, EoE literally enforces the spatial dimensions of embodied acting, the inside/outside divide, the reproduction of borders, and ties this to the fate of all humanity and planetary destruction in general.

In this sense, then, the film reveals the shortcomings of modern, anthropocentric individualism, exposing its inability to address ecological devastation by making an overt connection to the conception of a strictly discrete self, individual decision and external global destruction, while simultaneously displaying the ineffectiveness of such agential assumptions of individualistic selfhood to enact macro scale change. For instance, the moments when Shinji chooses to reinstate the barriers between people are presented with a somewhat positive inflection; it seems Shinji has saved his individual selfhood and humanity by extension, but this is only to unveil the twist: Shinji floats to the surface of an already dead world, where humanity has caused the end of life on a planetary scale. The film thus takes the logic of the autonomous individual, fully responsible for his (or her) actions on the world to its logical extreme and yet undermines it completely: on the one hand, it is a personal decision that leads to a massive, global disruption ("just one person can change the world"); on the other, Shinji's decisions do little to change the actual outcome as he is alone with only Asuka at the end of the world. While we may feel 
that Shinji made the right choice in selecting individualism, seemingly averting global disaster, the world has still ended, even though Shinji did not necessarily start it (with Gendō and/or SEELE as the actual catalyst).

Ultimately, despite its emphasis on a single individual's choice, the film is ambivalent with regard to an individual's agency in its finale, taking its agential assumptions to task: individuals' decisions are both ineffective and grandiose on a global scale. As Morton asserts, this is the strange problematic we humans must contend with in the Anthropocene, where individual output of pollution is in some ways statistically meaningless, but also clearly a part of the massive ecological catastrophe underway (20I8: xxvii). Such a dynamic of scale underpins the harrowing ecological vision provided by EoE: that despite Shinji's decision to reinstate human individualism, we are still left on a dead Earth, his individual actions only one part of the larger environmental destruction already underway. Instead of showing the strange fantasy of 'last man' narratives (surviving in a world after the fall of humanity) (Morton 20I8), EoE depicts the ecologically devasting catastrophe, directly tying it to explosive holisms and human individualism, exposing their inadequacy to act against the end of the world.

\section{References}

Azuma, H. (2009). Otaku: Japan's Database Animals. Minneapolis, MN: University of Minnesota Press. (Introduction and translation by J. E. Abel and S. Kono).

Butler, J. (1988). Performative Acts and Gender Constitution: An Essay in Phenomenonology and Feminist Theory. Theatre Journal, 40, 5I9-53I.

. (1993). Bodies that Matter: On the Discursive Limits of "Sex." London: Routledge. (1997). Excitable Speech: A Politics of the Performative. New

York: Routledge. 
Crafton, D. (2013). Shadow of a Mouse: Performance, Belief and WorldMaking in Animation. Berkeley, CA: University of California Press.

Diederichsen, D. (20I2). Animation, De-Reification, and the New Charm of the Inanimate. E-Flux Animism, Special Issue, I-I I.

Endō, T. (I997). Konna kitanai kirei na hi ni wa. In EVA no nokoseshi mono (ed. T. Shimotsuki) (pp. 80-93). Рорpu karuchā kuritīku. Tokyo: Seikyūsha.

Heise, U. (20I4). Plasmatic Nature: Environmentalism and Animated Film. Public Culture, 26, 30I-3 I8.

Kotani, M. (1997). Seibo Evangerion. Tokyo: Magazine House.

Lamarre, T. (2009). The Anime Machine: A Media Theory of Animation. Minneapolis, MN: University of Minnesota Press.

Latour, B. (1993). We Have Never Been Modern. Cambridge, Massachusetts: Harvard University Press.

Lukács, G. (2010). Scripted Affects, Branded Selves: Television, Subjectivity, and Capitalism in I 990 s Japan. Durham, NC and London: Duke University Press.

Maejima, S. (2010). Sekaikei to wa nani ka: posuto EVA no otakushi. Tokyo: Soft Bank Creative.

Morton, T. (2013). Hyperobjects: Philosophy and Ecology after the End of the World. Minneapolis, MN: University of Minnesota Press. . (20I7). Humankind: Solidarity with Nonhuman People.

London and New York: Verso. . (2018). Being Ecological. Cambridge, MA: MIT Press.

Murakami, T. (2005). Earth in My Window. In Little Boy: The Arts of Japan's Exploding Subculture (pp. 98-I49). New York and New Haven, CT: The Japan Society and Yale University Press. (Translated by L. Hoaglund)

Steinberg, M. (2012). Anime's Media Mix: Franchising Toys and Characters in Japan. Minneapolis, MN: University of Minnesota Press.

Suan, S. (20I7). Anime no 'kōisha': Animēshon ni okeru taigenteki/ shūjiteki pafōmansu ni yoru 'jiko.' Animēshon kenkyū, I9(I), 3-I 5 . 
(2018). Consuming Production: Anime's Layers of Transnationality and Dispersal of Agency as Seen in Shirobako and Sakuga-Fan Practices. Arts, 7(3), 27. Retrieved from: DOI: https:// doi.org/I0.3390/arts7030027

Thouny, C. (2009). Waiting for the Messiah: The Becoming-Myth of Evangelion and Densha Otoko. Mechademia, 4, I I I-I 29.

Uno, T. (2008). Zeronendai no sōzōryoku. Tokyo: Hayakawa Shobō. 